ISSN $1676-3742$

\title{
O culto mariano e o arquétipo do feminino: elementos antropológicos e psicológicos
}

\author{
The Marian Worship and the Archetype of Feminine: \\ Anthropological and Psychological Elements
}

Pedro K. Iwashita

\section{Resumo}

O desenvolvimento do dogma marial demonstra a importância do culto, dos símbolos, da vivência e principalmente da fé viva ou vivida. É importante que o dogma mantenha contato com essa fé viva da Igreja, com o sensus fidei ou sensus fidelium, para que não se transforme em uma fórmula rígida sem ligação com a vida. Nesta perspectiva foi importante a publicação pela Comissão Teológica Internacional do documento: "Sensus fidei na vida da Igreja", declarando que todos os batizados participam na missão profética de Jesus Cristo e que o Espírito Santo unge e equipa-os para essa vocação, conferindo-lhes um conhecimento muito pessoal e íntimo da fé da Igreja. É esta fé da Igreja que tem atuado também na definição dos dogmas marianos. Do ponto de vista psicológico Jung constatou, no movimento popular pela definição dogmática da assunção de Maria, a expressão de profundas exigências da psique por uma transformação do arquétipo do feminino. A dogmatização da Assunção veio ao encontro dessa expectativa do "sensus fidelium", de glorificação do feminino em Maria, a mutação do arquétipo até a dimensão da Anima Sabedoria.

Palavras-chave: Sensus fidei. Igreja. Dogma. Arquétipo. Feminino. 


\begin{abstract}
The development of Marian dogma demonstrates the importance of worship, symbols, and especially the experience of living and lived faith. It is important that the dogma in touch with the Church's living faith, with the sensus fidei or sensus fidelium so that does not become a rigid formula unrelated to life. In this perspective was important the publication by the International Theological Commission the document: "Sensus Fidei in the life of the Church", declaring that all the baptized participate in the prophetic mission of Jesus Christ and the Holy Spirit anoints and equips them to this vocation, conferring them a very personal and intimate knowledge of the Church's faith. It is this faith of the Church that has worked also in the definition of the Marian dogmas. From a psychological point of view Jung found in the popular movement for the dogmatic definition of the Assumption of Mary, the expression of profound needs of the psyche through a transformation of the feminine archetype. The dogma of the Assumption came to meet this expectation of "sensus fidelium", the glorification of women in Mary, the mutation of the archetype to the dimension of the Anima as Sapientia.
\end{abstract}

Keywords: Sensus fidei. Church. Dogma. Archetype. Feminine.

\title{
Introdução
}

Na história do desenvolvimento do dogma mariano, o culto, os símbolos, a vivência, a experiência, mas, sobretudo, a fé vivida, precederam as proclamações dogmáticas oficiais. Em vista disso, é importante que o dogma mantenha contato permanente com a fé viva da Igreja, pois de outra forma corre-se o risco de se tornar uma fórmula rígida, petrificada, sem nenhuma sintonia com a vida. Com efeito, faz-se necessário lembrar, também, que o vivido, o implícito é muito mais vasto que aquilo que a palavra é capaz de explicitar. O desenvolvimento do dogma supõe que esse implícito se torne sempre mais explícito, ${ }^{1}$ sem que haja mudança no seu conteúdo formal, pois não se trata de adição de verdades, e sim da clarificacão da verdade, ${ }^{2}$ o que

${ }^{1}$ Cf. HÖFER, J.; RAHNER, K. (org). Lexikon für Theologie und Kirche, Freiburg im Breisgau: Herder, 1955-1967, reimpressão sem modificação em 1986 (Sonderausgabe) 4, p. 957, doravante citado com a sigla LThK.

${ }^{2}$ Cf. TILlard,J.-M. R. Foi populaire et foi savante. Actes du Ve Colloque du Centre 
valeria, sobretudo, para os dogmas marianos, cujas definições têm-se apoiado sobre o vivido da fé dentro da Igreja, a saber, sobre o "sensus fidelium" ou "sensus fidei"".

A noção de "sensus fidelium" ou "sensus fidei", 5 deriva da doutrina

d'études d'histoire des religions populaires tenu au Collège doninicain de théologie (Ottawa). Cogitatio Fidei 87. Paris: Cerf, 1976, p. 32: "O progresso dogmático não diz primeiramente adição de verdades, mas clarificação da verdade".

3 "Sensus fidelium", "sensus fidei", são termos correntes na linguagem teológica para designar o sentido cristão ou o sentido da fé. A denominação "sensus fidei" seria, segundo Dillenschneider, a menos equivoca. Cf. DILLENSCHNEIDER, C. Le sens de la foi et le progrès dogmatique du mystère marial. Roma, 1954, p. 317. A fórmula "sensus fidelium" pode dar às vezes a impressão de que se trataria somente da fé dos simples, do povo, quando na verdade, os representantes do Magistério, eles também, são fiéis autênticos. Id., p. 318. Para evitar esse inconveniente, alguns autores preferem servir-se de um termo de alcance mais geral, falando em "sentido da fé" ou "sentido cristão": fala-se mesmo em "consciência da fé" ou "consciência da Igreja". A Constituição Apostólica "Munificentissimus Deus" (AAS 42, 1950; DH, 3900-3904) de PIO XII usa muito as expressões "Christiani populi fides", "communis fides Ecclesia", que algumas vezes fazem referência aos elementos objetivos da fé abraçados pelo corpo eclesial sob a graça do Espirito Santo. Id., p. 318. Nesse nosso estudo utilizaremos alternadamente o termo "sensus fidelium" e "sensus fidei", o que faz também o documento da Comissão Teológica Internacional sobre o Sensus fidei.

${ }^{4}$ Cf. COMISSÃO TEOLÓGICA INTERNACIONAL. O Sensus Fidei na vida da Igreja. (Documentos da Igreja 21). Brasília: Edições CNBB, 2015, doravante citada com a sigla SF.

${ }^{5} \mathrm{O}$ documento da Comissão Teológica Internacional é muito oportuno, porque o conceito não tinha sido até hoje estudado de maneira suficiente seja do ponto de vista histórico seja do ponto de vista sistemático. Cf. LThK 4, p. 947. Os estudos mais conhecidos eram os de: DILLENSCHNEIDER, C. Le sens de la foi el le progrès dogmatique du mystère marial. Roma, 1954; CONGAR, Y. Le peuple fidèle et la fonction prophétique de l'Eglise». Irenikon 24 (1951), pp. 289-312, pp. 440-466; id., Jalons pour une théologie du laïcat, (coll. « Unam Sanctam » 23) Paris, 1954, pp. 369-407; Les laïcs et la fonction prophetique de l'Eglise, Paris; KOSTER, D. Volk Gottes im Wachstum des Glaubens, Heidelberg, 1955; MARIN-SOLA, F. L'évolution homogène du dogme catholique. $2^{\mathrm{a}}$ ed. Fribourg, 1924; RADEMACHER, A. Entwicklungsgedanke in Religion und Dogma. Köln, 1924. Uma obra muito interessante que procura estudar o aspecto teológico da chamada "fé popular" ou "cristianismo popular" é: Foi populaire et foi savante. Actes du $\mathrm{V}^{\mathrm{e}}$ Colloque du Centre d'études d'histoire des religions populaires tenu au Collège doninicain de théologie (Ottawa). Paris, 1976. Os estudos mais interessantes para a nossa pesquisa foram entretanto: DILLENSCHNEIDER, C., Le sens de la foi et le progrès dogmatique du mystère marial, Roma, 1954; TILLARD, J.-M.R., «Le 'sensus fidelium'. Réflexion Théologique». In: Foi populaire et foi savante, Cogitatio Fidei 87, pp. 9-40, Paris, 1976. Cf. TILLARD, J.-M.R., «Théologie et vie ecclésiale». In: Initiation à la pratique de la théologie, $t$. I, Paris, 1982, pp. 161-182, e agora o mais recente documento da COMISSÃO TEOLÓGICA INTERNACIONAL. O Sensus Fidei na vida da Igreja. (SF) Documentos da Igreja 21. Brasília: Edições CNBB, 2015. Completando as fontes, temos ainda o estudo de Bernard Sesboüé: O Magistério em questão. Autoridade, verdade e liberdade na Igreja. Petrópolis: Vozes, 2004; Fisichella, R. Verbete: Sensus fidei. In: LEXIKON. Dicionário Teológico 
fundamental sobre as potências da fé, pelas quais o fiel é capacitado para pressentir e perceber, como por instinto, as virtualidades escondidas do depósito revelado. ${ }^{6}$ Trata-se de "sentido" oriundo da fé, por tudo aquilo que se refere a essa mesma fé. Ele possibilita uma espécie de julgamento instintivo ${ }^{7}$ em relação ao conteúdo da fé, sem ser instinto em si, mas forma especial de conhecimento. O conhecimento fornecido por ele não é tanto o resultado de trabalho de conceptualização, mas de experiência concreta, que espontaneamente aparece em consequência das experiências e dos conhecimentos precedentes. ${ }^{8}$ Consiste, assim, numa percepção da realidade da fé, muitas vezes mais intuitiva do que raciocinada, vinda do Espírito Santo, ${ }^{9}$ pela qual o fiel é capacitado a discernir, na comunhão da Igreja, as virtudes do dado revelado, que lhe é objetivamente proposto pelo Magistério. ${ }^{10} \mathrm{O}$ "sensus fidelium" não é, portanto, essencialmente um produto da nossa sensibilidade cristã. Ele deve se apoiar sobre o fundamento objetivo do dado revelado, "pois a fé vem da pregação e a pregação é pela palavra de Cristo" $(\mathrm{Rm} 10,17) .{ }^{11}$

\section{Comissão Teológica Internacional e o conceito de "Sensus fidei"}

O surpreendente documento do Vaticano, elaborado pela Comissão Teológica Internacional ${ }^{12}$ declara que, "pelo dom do Espírito Santo “, o Espírito da Verdade que vem do Pai" e dá testemunho do Filho (Jo 15,26), todos os batizados participam na missão profética de Jesus Cristo, "a Testemunha fiel e verdadeira" (Ap 3,14). Eles devem dar testemunho do Evangelho e da fé apostólica na Igreja e no mundo. O Espírito Santo unge e equipa-os para essa

Enciclopédico. São Paulo: Loyola, 2003, pp. 690-691; NARCISSE, Gilbert. Sensus fidei. In: Dicionário Crítico de Teologia. São Paulo: Paulinas - Loyola, 2004, pp. 1632-1634.

${ }^{6} \mathrm{Cf}$. SF 2.

${ }^{7}$ SF 2: "Como resultado, os fiéis têm um instinto para a verdade do Evangelho, o que lhes permite reconhecer e autenticar autêntica doutrina e prática cristã, e rejeitar o que é falso. Esse instinto sobrenatural, intrinsecamente ligado ao dom da fé recebida na comunhão da Igreja, é chamado de sensus fidei, e permite aos cristãos cumprir a sua vocação profética".

${ }^{8}$ Cf. LThK 4, pp. 945-946.

${ }^{9}$ Cf. TILLARD, J.-M.R. «Le `sensus fidelium'. RéflexionThéologique». In: Foi populaire et foi savante (Cogitatio Fidei 87), pp. 9-40, Paris, 1976, p. 25.

${ }^{10} \mathrm{Cf}$. DILLENSCHNEIDER, C. Le sens de la foi et le progrès dogmatique du mystère marial. Roma, 1954, p. 327.

${ }^{11} \mathrm{Cf}$. SF 3.

${ }^{12}$ COMISSÃO TEOLÓGICA INTERNACIONAL. O Sensus Fidei na vida da Igreja. (SF). (Documentos da Igreja 21) Brasília: Edições CNBB, 2015. 
vocação, conferindo-lhes um conhecimento pessoal e íntimo da fé da Igreja. Na primeira carta de São João, é dito aos fiéis: 'vós fostes ungidos da parte do Santo, e todos vós tendes conhecimento', 'a unção que vós recebestes do [Cristo] permanece em vós, e assim vós não precisais de ninguém para ensinar-vos', 'sua unção vos ensina a respeito de todas as coisas' (1Jo 2,20,27)" (SF 1).

Conforme o documento, isso significa que "os fiéis têm um instinto para a verdade do Evangelho, o que lhes permite reconhecer e autenticar a verdadeira doutrina e prática cristã, e rejeitar o que é falso. Esse instinto sobrenatural, intrinsecamente ligado ao dom da fé recebida na comunhão da Igreja, é chamado sensus fidei, e permite aos cristãos cumprir a sua vocação profética, ${ }^{13} \mathrm{e}$ isto respondendo àquilo que corresponde a sua própria estrutura antropológica, homem e mulher criados à imagem de Deus seu Criador. ${ }^{14} \mathrm{O}$ ser humano é criado como indivíduo separado, "porém designado para ser-com-o-outro e com os demais, (...) desde o princípio é, essencialmente, um ser-comunial-erelacional, ser que é, ao mesmo tempo, indivíduo e coletivo"15.

Essa realidade antropológica está subjacente à noção de sensus fidei presente no documento da Comissão. Esse sensus fidei é visto pelo Documento como um recurso vital para a nova evangelização a que a Igreja está fortemente empenhada em nosso tempo (SF 2). Aqui é importante a declaração dada pelo documento da Comissão Teológica Internacional:

"Como conceito teológico, o sensus fidei refere-se a duas realidades distintas, embora intimamente conexas; o sujeito próprio de uma é a Igreja, "coluna e fundamento da verdade" (1Tm 3,15), enquanto que o sujeito da outra é cada crente, que pertence à Igreja devido aos sacramentos da iniciação e que participa da fé e da vida da Igreja, particularmente através da celebração regular da Eucaristia. De uma parte, o sensus fidei refere-se à aptidão pessoal que tem um crente, no seio da comunhão da Igreja, para discernir a verdade da fé. Por outro lado, o sensus fidei refere-se à uma realidade comunitária e eclesial: o instinto da fé da própria Igreja, por meio do qual ela reconhece o seu Senhor e proclama sua palavra. $\mathrm{O}$ sensus fidei entendido neste sentido se reflete no fato de que os batizados

\footnotetext{
${ }^{13}$ Cf. SF 2.

${ }^{14}$ Cf. "Sensus fidei: Uma ponte entre academia e hierarquia", in: Lukas Lui. Dissertação de Mestrado: A Igreja do Espírito de Deus que nasce no coração do povo. A relevância e o desafio do sensus fidei na Constituição dogmática Lumen Gentium do Vaticano II. PUC/Rio, 2010, p. 64. Disponível em: http://www.maxwell.vrac.puc-rio.br/16843/16843_4.PDF

${ }^{15}$ Ibidem, p. 65.
} 
convergem em uma adesão vital a uma doutrina de fé ou a um elemento da práxis cristã. Esta convergência (consensus) desempenha um papel vital na Igreja. O consensus fidelium é um critério seguro para determinar se uma doutrina ou uma determinada prática faz parte da fé apostólicas. No presente documento usamos o termo sensus fidei fidelis para nos referir à capacidade pessoal do crente de fazer um discernimento justo em matéria de fé, e o de sensus fidei fidelium para nos referir ao instinto de fé da própria Igreja. Dependendo do contexto, sensus fidei irá referir-se a um ou a outro sentido, e, para o segundo significado, será utilizado também o termo sensus fidelium. "'16

O documento da Comissão Teológica Internacional traz assim precisões importantes na definição do conceito de sensus fidei e sensus fidelium, permitindo-nos continuar na pesquisa desse tema relacionando-a ao culto mariano.

\section{Critérios para a validade da atuação do sensus fidei ou sensus fidelium}

Para o simples fiel como para o teólogo, a fonte objetiva de todo desenvolvimento da fé é o depósito revelado proposto pelo Magistério da Igreja. Não é suficiente que os fiéis aceitem em comum, em dado momento da história, tal crença, tal fato incluído em uma solenidade litúrgica ou tal prática de piedade, para que sejam consideradas como verdades certas. Com efeito, pode existir aqui unanimidade no sentimento cristão em tomo de um simples fato histórico, de uma prática religiosa que não tem nenhuma ligação com o "depositum fidei". ${ }^{17} \mathrm{O}$ valor criteriológico do "sensus fidei" é garantido na comunhão dos fiéis com o Magistério, a quem cabe guiar e controlar o "sensus fidei" na comunidade eclesial; inquirir, antes de se pronunciar sobre o vigor desse sentido comunitário; enfim, graças ao carisma da infalibilidade, de que é provido, interpretar e julgar a crença comum que é a tradição viva da Igreja $^{18} \mathrm{~A}$ tradição atual viva da Igreja representa justamente o sentido cristão universal, através da qual "o Espírito Santo dá testemunho de si mesmo" em toda a Igreja. ${ }^{19}$

${ }^{16} \mathrm{SF} 3$.

${ }^{17}$ DILLENSCHNEIDER, C. Le sens de la foi et le progrès dogmatique du mystère marial. Roma, 1954, p. 328. Cf. SF 3.

${ }^{18}$ Ibidem., pp. 342-343.

${ }^{19}$ Ibidem., pp. 370-371. 
Mas "o sensus fidelium" não pode ser identificado simplesmente com a obediência dos fiéis aos ensinamentos do Magistério. Evidentemente não se concebe um "sensus fidelium" que não esteja à escuta do Magistério. Mas ele é mais do que isso. Fosse somente uma obediência diligente dos fiéis para dar seu assentimento à doutrina proposta pela "Ecclesia docens" não seria mais fator de explicitação dogmática. Nesse caso somente o Magistério o seria. Mas a história da doutrina marial sinaliza, tanto a da Imaculada Conceição como a da Assunção, que antes mesmo de existir uma declaração normativa do Magistério, o "sensus fidelium" produziu muitas vezes e irresistivelmente tais virtualidades do dado marial. Permanecendo sob a vigilância do Magistério, o "sensus fidelium" precedeu e preparou assim o ensinamento formal dado pelo mesmo. O "sensus fidelium" não é, portanto, a simples "obedientia fidei". ${ }^{20}$

A ação específica do Magistério e o comportamento dos fiéis seriam princípios complementares da adesão da Igreja a um dado que vem do Espírito Santo. Cortado dessa referência essencial à "verdade vivida" que o precede e o condiciona, o ato do Magistério implicado naquilo que se chama "definição dogmática" não teria mais sentido, pois seria decisão sem objeto. Isto parece, de maneira especial, importante para as duas definições dogmáticas evocadas acima, a saber, a da Imaculada Conceição e a da Assunção. Ali, o material assumido, polido na definição, constitui o "sensus fidelium". O fato da definição não deve fazer esquecer, no entanto, que a fixação em fórmulas precisas não suprime o fato de que se trata da intervenção do Magistério apoiando-se sobre duas correntes de fé e de devoção popular. Não se julga, portanto, o dogma definido por Pio XII da mesma maneira como se julga Nicéia, pois se trata de registros diferentes. As grandes definições conciliares visavam ao próprio núcleo do dado da fé, enquanto os dois últimos dogmas foram motivados não tanto pela necessidade de defender a fé; e sim pela necessidade de fixar o fervor popular. ${ }^{21}$

O dogma definido não deve, pois, perder o contato com o vivido que o precedeu e que o precede. A corrente da vida e da devoção do povo fiel desborda sob os rigorosos conceitos das formulações dogmáticas, atraindo consigo uma onda de sentimentos, de atitudes do coração, que as locuções formais não podem chegar a fixar. ${ }^{22}$ Essa corrente de vida e de devoção que se constata na

${ }^{20} \mathrm{Ib} .$, pp. 320-322.

${ }^{21}$ Cf. TILLARD, J,-M.R. «Le `sensus fidelium'. RéflexionThéologique». In: Foi populaire et foi savante, Cogitatio Fidei, Paris, 1976, p. 19.

${ }^{22} \mathrm{Ib} .$, p. 36. 
liturgia e na vida de oração da Igreja, nos dá idéia da amplidão do vivido. E a "lex orandi lex credendi" que exprime melhor essa realidade. ${ }^{23}$ Segundo a Tradição, a oração "diz a fé", por um modo que se traduz mal em conceitos, tratando-se de uma afirmação "sui generis" da certeza da fé, nela e por procedimento coletivo tecido de sinais, repleto de sentimentos, não desdenhando a linguagem da poesia e da música. Na liturgia, o ato do culto, também quando é mais gestual que verbal, apoia-se sobre a mesma verdade que a confissão do símbolo batismal. Ele a proclama, todavia, por outra linguagem que não aquela de conceitos com conteúdos precisos. A certeza veiculada pelos atos e atitudes precedeu aquela que traz o texto. A verdade brotou assim "fazendo-se". ${ }^{24}$

\section{Sensus fidei e fé popular}

O "sensus fidelium", com todo o seu potencial de vivência e de sentimentos, representa, dito analogicamente, o inconsciente coletivo da Igreja. Evidentemente, o "sensus fidelium" é uma realidade da fé, portanto espiritual, promovido pelo Espírito Santo. Mas se aproximamos o "sensus fidelium" à "fé popular" ${ }^{25}$ somos levados a nos ocupar também com a questão da "religião popular", que em princípio não se identificam, simplesmente porque fé e religião se distinguem mutuamente. Mas se queremos perceber o homem concreto com todos os apelos do ser e as raízes que o inserem no mundo, a fé não pode prescindir da religião. Ora sabe-se que a religião pode se manifestar com sentimento ou necessidades mais ou menos puras. Acontece também que algumas de suas manifestações instintivas tenham a cor da ingenuidade, aparecendo aos olhos dos especialistas como simplismo pré-racional. Mas cortar a fé da dimensão religiosa do homem é condená-la à extinção, é tirá-la de seu húmus natural. ${ }^{26}$

No que se refere à relação entre sensus fidei e fé popular, à apresentação clássica de Clément DILLENSCHNEIDER ${ }^{27}$, temos também a de J.-M.R. TILLARD, que faz a distinção entre "fé popular" e "fé erudita"28. Os

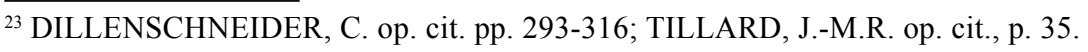

${ }^{24}$ Cf. TILLARD, J,-M.R. «Le ‘sensus fidelium'. RéflexionThéologique». In: Foi populaire et foi savante (Cogitatio Fidei) Paris, 1976, p. 35.

${ }^{25}$ Cf. SF $107-112$.

${ }^{26} \mathrm{Ib} .33$.

${ }^{27}$ DILLENSCHNEIDER, Cl. Le sens de la foi et le progrès dogmatique du mystère marial. Roma, 1954.

${ }^{28}$ Cf. TILLARD,J.-M. R. Foi populaire et foi savante. Paris, 1976, pp. 9-12. 
teólogos representariam nesse caso a "fé erudita", encontrando-se em face ao grupo formado pela hierarquia e pelos fiéis, que muitas vezes se encontram na adesão a alguma prática da "fé popular". Basta ver, por exemplo, a lista de devoções que a hierarquia, talvez sem promovê-las, mas que não hesita em aceitar e honrar com o seu patrocínio, enquanto os teólogos as considerariam problemáticas. ${ }^{29}$ Não se trata aqui de opor "fé popular" à "fé erudita", e nem de botá-las em concorrência uma contra a outra. Além disso, "popular" não se opõe aqui a clerical. É sabido que mesmo clérigos, bispos e papas, em suas devoções pessoais, e até em certos atos oficiais, se associam aos movimentos da fé popular, e se alimentam disso. Cristãos instruídos e membros da hierarquia têm em sua vida privada devoções que traduzem visões, as quais não saberiam justificar teologicamente e de maneira convincente. Não se trata aqui de duplicidade ou falta de lógica, mas de uma consequência da natureza da fé. A realidade englobada na vida da fé vai além do núcleo delimitado pelas fórmulas dogmáticas. ${ }^{30}$

Conforme o Documento da Comissão Teológica, pode-se dizer que a religiosidade popular é "bem orientada" quando é verdadeiramente "eclesial'. Papa Paulo $\mathrm{VI}^{31}$ indicou também certos critérios para a eclesialidade da religiosidade popular. Ser eclesial significa ser alimentada pela Palavra de Deus, não ser politizada ou presa a ideologias, mantendo-se fortemente em comunhão tanto com a igreja local quanto com a Igreja universal, com os pastores da Igreja e com o magistério, e sendo fervorosamente missionária. Esses critérios indicam as condições necessárias para a autenticidade tanto da religiosidade popular quanto do sensus fidei que lhe está subjacente. Na sua forma autêntica, como o critério final indica, ambos são ótimos recursos para a missão da Igreja. Papa Francisco destaca a "força missionária" da piedade popular, em que pode ser visto uma referência para o sensus fidei, não subestimando o poder evangelizador subjacente à piedade popular, pois ao fazer isso deixaríamos de reconhecer a obra do Espírito Santo. (SF 112).

${ }^{29}$ Ibidem, pp. 10-11.

${ }^{30}$ Cf. TILLARD, J.-M. R., op. cit., pp. 31-32.

${ }^{31}$ Papa Paulo VI. Exortação Apostólica Evangelii Nuntiandi (1975), $\mathrm{n}^{\circ} 48$. No discurso de abertura da quarta conferência latino-americana do CELAM, Papa João Paulo II disse que a religiosidade popular com suas raízes essencialmente católicas, era um antídoto contra as seitas e a garantia de fidelidade à mensagem de salvação. Cf. Documnto de Santo Domingo, $\mathrm{n}^{\circ} 12$. Papa Francisco, por sua vez, afirma que se a fé cristã está verdadeiramente inculturada, a piedade popular é uma importante parte do processo na qual o povo se evangeliza continuamente. Cf. Evangelii Gaudium, 122. 


\section{Pressupostos psicológicos do sensus fidei na perspectiva junguiana: elementos arquetípicos do culto marial}

É esse húmus, a dimensão religiosa do homem, sobre o qual a fé deverá estar plantada, que chamou a atenção de C. G. Jung, e que o levou a descobrir novas dimensões e nova maneira de valorizá-lo. Desse modo a psicologia da profundidade veio trazer contribuição importante para a compreensão do fundo psicológico do "sensus fidelium". O que se diz sobre Maria, do ponto de vista da psicologia da profundidade, pode ser considerado tentativa de elucidação do fundo psicológico do "sensus fidelium" concernente ao culto marial. Essa utilização da psicologia junguiana aqui não quer significar uma absolutização da mesma em detrimento das outras escolas. A escolha é devido à importância que C.G.Jung deu ao fenômeno religioso, e a acolhida que essa leitura encontrou no meio teológico católico ${ }^{32}$ procurando estar ao mesmo tempo conscientes do caráter hipotético das afirmações, que poderão ser ou não confirmadas pela experiência.

Tentaremos aqui explorar o aspecto sobre Maria como figura da Anima ${ }^{33}$. Maria é a realização suprema da sabedoria ${ }^{34}$ no plano histórico, tendo repetido em si o itinerário sapiencial, que já fora de seu povo, de quem é filha, memorizando e recordando os fatos salvíficos, os feitos de Deus; atenta à profundidade escondida da Revelação, sendo custódia da Palavra e tendo parentesco com a sabedoria na escuta de Jesus-Sabedoria, e sendo por isso a Filha da Sabedoria por excelência, e "trono da sabedoria", por ter trazido o Verbo no seu seio e no seu coração.

$\mathrm{Na}$ sua perspicácia, C. G. Jung constatara, no movimento popular pela definição dogmática da assunção de Maria, a expressão de profundas exigências da psique por uma transformação do arquétipo do feminino. A dogmatização da Assunção veio ao encontro dessa expectativa do "sensus fidelium", de glorificação do feminino em Maria, a mutação do arquétipo até a dimensão da Anima Sabedoria.

\footnotetext{
${ }^{32}$ Cf. CUCCI, Giovanni, S.J. Il simbolo in Psicanalisi. Il contributo di Jung. Civiltà Cattolica (2011) no 3875, pp. 425-530; GIUCHEDI, F. Carl Gustav Jung. Aspetti psicologici dell uomo religioso. Civiltà Cattolica CXXXII (1981), pp. 250-266.

${ }_{33}$ Anima é o arquétipo do feminino na psique masculina. Cf. JUNG, C. G. GW (Gesammelte Werke $=$ Obras Completas) 14/1: Mysterium Coniunctionis. Olten und Freiburg im Breisgau: Walter Verlag, § 69

${ }^{34}$ BOUYER, L. Le trône de la sagesse. Essai sur la signification du culte marial. Paris: Cerf, 1957.
} 
Evidentemente, tal experiência não se operou na consciência, mas sim no interior do inconsciente coletivo. Para C. G. Jung, que durante anos vinha observando empiricamente a alma humana, o dogma da Assunção pareceu-lhe um acontecimento de extrema importância para certos temas fundamentais que ocupavam o centro de suas preocupações, tais como, a redenção do feminino na psique humana, sua integração no conceito de Deus, a "conjunctio oppositorum", o "hiero gamos", o casamento sagrado e celeste. São realidades que devem acontecer no interior da psique, na transformação e mutação da energia psíquica pelo processo de individuação, mas que tiveram uma expressão histórica na Assunção. Não se trata aqui de projetar sobre o dogma um processo psíquico, mas de constatar que o dogma faz justiça às leis arquetípicas.

A Anima representa o caráter mutacional da Grande Mãe, ${ }^{35}$ que por sua vez representa o caráter elementar do arquétipo do feminino. Segundo Neumann, o caráter mutacional se encontra no desenvolvimento psíquico, inicialmente sob a "hegemonia" do caráter elementar, de cujo domínio se destaca pouco a pouco, e sua ação se faz sentir já na função fundamental do feminino maternal, na gestação e no nascimento, no ato de dar à luz. Também a função de nutrição, que pode ser atribuída tanto ao caráter elementar como ao mutacional, depende do acento que se dá à tendência para a conservação do que existe ou para a sua expansão e mudança. Isso quer demonstrar que os dois caracteres não se excluem, mas se interpenetram e se ligam desde o início de múltiplas maneiras, e é somente em raras e extremas constelações que encontramos um dos caracteres isoladamente, e mesmo ambos estando presentes ao mesmo tempo, trata-se quase sempre da dominância ou da predominância de um sobre o outro. ${ }^{36} \mathrm{O}$ aparecimento de nova fase não significa incondicionalmente a eliminação da que precede. Com efeito, o caráter elementar, como o total domínio do "Grande Círculo", contém em si o caráter mutacional desde o início, e mesmo que venha a mutação, ele se desdobra transformante e transformado no próprio círculo do eterno equilíbrio. ${ }^{37}$

\footnotetext{
${ }^{35} \mathrm{Na}$ psicologia analítica a Grande Mãe representa um aspecto especial do arquétipo e da figura da mãe. É uma das imagens primordiais atuantes na psique, e que não se deixa derivar da experiência com uma mãe concreta. $\mathrm{O}$ conceito foi assumido da história das religiões, e serve para a indicação de símbolos transcendentais, como, por exemplo, os das deusas mães. Cf. NEUMANN, E. Die Grosse Mutter. Eine Phänomenologie der weiblichen Gestaltungen des Unbewussten. Olten und Freiburg im Breisgau: Walter Verlag, 1981.

${ }^{36}$ NEUMANN, E. Die Grosse Mutter, 43.

${ }^{37}$ Ibidem, 43.
} 
O vir-a-ser-do-homem exige a ascensão a partir das profundidades escuras do feminino-maternal-inconsciente em direção à claridade do ser homem e mulher integral, e total. O filho deve se tornar homem adulto, deixando de projetar o feminino, que está nele, como negativo sobre as mulheres reais, mas integrá-lo como fazendo parte de sua própria psique. Em linguagem arquetípica, isto significa que o homem deverá destacar, a partir do arquétipo da Grande Mãe, o aspecto da Anima, e fazer do feminino a parceira psíquica consciente dentro de si mesmo, de modo que a Anima se torne ajuda no processo do vir-a-ser homem total. Somente se o homem cultiva a sua Anima, a Grande Mãe deixará de dominar sobre a sua psique masculina. Aqui se encontra também a oportunidade para o vir-a-ser integral da mulher, deixando de se identificar com a Grande Mãe. Na mulher, a Grande Mãe deve se transformar psiquicamente na mulher consciente com o Eu fortalecido, cuja identidade não deverá mais ser dirigida, como até agora na nossa civilização, pelo Eu-consciência do homem, mas que deverá ser autenticamente feminina. ${ }^{38}$

\section{Culto marial e mutação do arquétipo da anima}

Enquanto a Anima permanecer como conteúdo inconsciente ou fixo à Grande Mãe, agirá como complexo autônomo, provocando o fenômeno da possessão e da projeção. ${ }^{39} \mathrm{Na}$ verdade, todos os conteúdos inconscientes, enquanto permanecerem como tais, ou seja, não integrados à personalidade, exprimir-se-ão como fenômenos de Anima e do Animus ${ }^{40}$. Através da conscientização desses conteúdos chegar-se-á à raiz dos complexos, à libertação da possessão e ao mesmo tempo dos fenômenos da Anima, que se tornará então preciosa função de relação com o inconsciente. ${ }^{41}$

\footnotetext{
38 Cf. KASSEL, M. Weibliche Aspekte im lukanischen Kindheitsevangelium. Diakonia (Nov. 1984), p. 391.

${ }^{39}$ Projeção é a transferência para o exterior, para uma pessoa ou para um objeto, de conteúdos psíquicos próprios do inconsciente, por exemplo, a projeção do arquétipo da anima sobre uma determinada mulher. Cf. JUNG, C. G. GW 7: Zwei Schriften über Analytische Psychologie. Über die Psychologie des Unbewussten. Die Beziehungen zwischen dem Ich und dem Unbewussten, $\$ 387$.

${ }^{40}$ Animus é o arquétipo do masculino no inconsciente da mulher. Cf. Zwei Schriften über Analytische Psychologie. Über die Psychologie des Unbewussten. Die Beziehungen zwischen dem Ich und dem Unbewussten, §196-340.

${ }^{41} \mathrm{Ib} ., \S 387$.
} 
Mas a simples conscientização não basta, pois a confrontação e a integração da Anima é verdadeiro desafio moral, que exige longa confrontação. Se essa confrontação for leal, autêntica e sincera, passar-se-á do estado de projeção para verdadeira mutação interior. A relação com a Anima representa para o homem prova de coragem; ordálio de fogo, para a sua força moral e espiritual. Em vista disso, prefere-se manter a origem desse desafio na condição de projetado. Para o homem da antiguidade, a Anima aparece como deusa ou como bruxa; enquanto o homem da Idade Média substitui a deusa pela Regina Coeli e pela Mãe Igreja. ${ }^{42}$ Mas enquanto a Anima permanecer em estado de projetado, fica-se sob a sua possessão e fascinação, que pode ser positiva ou negativa. $\mathrm{O}$ estado de projeção da Anima, por exemplo, pode conduzir à esterilidade psíquica e ao consequente fenômeno do dualismo, em que a Virgem Maria encarnaria tudo o que é positivo do feminino, e Eva e as mulheres reais encarnando tudo o que é negativo, a saber, a sedução e o pecado.

A Igreja, como Maria, é portadora da Anima, isto é, capaz de acolher, enquanto símbolos, a projeção da Anima. Isso explicaria talvez o fato de que tanta tinta já correu para descrever as glórias de Maria e da Igreja. ${ }^{43}$ Assim é que certa literatura mariana trai uma possessão pela fascinação da Anima. E o que se percebe hoje também em certa literatura a favor do feminismo ou da mulher, saídas da pena de homem. A fascinação em si nada tem de negativo, mas quando se trata de descrever uma realidade pode-se deturpá-la. Assim a fascinação leva a descrever a realidade da mulher de tal maneira, que acaba negando-lhe o direito de ser humana, isto é, com virtudes e defeitos, ambivalentes, como tudo o que é humano, o que redunda em nova forma de opressão e de machismo, pois as mulheres serão obrigadas a corresponder à imagem ideal, produto da fascinação. Em nível eclesial, tanto o recalque do feminino como a fascinação diante do mesmo podem ser obstáculo na integração das mulheres, e para o fato de serem acolhidas como parceiras na vida e no ministério por parte dos homens.

A integração da Anima exige, pois, que o feminino seja confrontado em toda a sua extensão de arquétipo fundamental do inconsciente, em sua polaridade positiva e negativa. $\mathrm{O}$ fenômeno da fascinação deve levar o homem a entrar em contato com o feminino dentro de si, pois o que parece atrair fora já se encontra dentro de si. O que parece causar repulsa fora, também se

${ }^{42}$ Cf. JUNG, C.G. Die Archetypen und das kollektive Unbewusste GW 9/I, 1985, §61.

${ }^{43}$ Cf. UNTERSTE, H. Theologische Aspekte der Tiefenpsychologie von C.G.Jung. Düsseldorf, 1977, pp. 235-238. 
encontra dentro de si, pois se trata do polo negativo do arquétipo. É preciso, pois retirar a projeção e desmontar a fascinação, para que se possa criar uma relação objetiva e construtiva, e integrar o arquétipo na sua ambivalência e na sua polaridade positiva e negativa.

$\mathrm{Na}$ escala dos quatro de C. G. Jung: Eva, Helena de Tróia, Maria e Sofia, que representam as quatro dimensões da anima, a Sabedoria ou a Sofia é, segundo Marie-Louise von Franz, raramente alcançada pelo homem moderno. ${ }^{44}$ Essas quatro figuras, que do ponto de vista filogenético têm-se articulado na história, podem com efeito, do ponto de vista ontogenético, se articular na psique do homem moderno, como fases da evolução do feminino na sua psique. Mas essa evolução depende de certos parâmetros culturais e das atitudes concretas que o homem toma em relação à Anima e à mulher real, considerando-a como Eva, Helena de Tróia, Maria ou Sofia. ${ }^{45}$

A razão pela qual o nível da Sabedoria é raramente alcançado pelo homem moderno talvez esteja no fato de que a experiência da Anima ficou estacionada no primeiro e no segundo nível, sendo a mulher real sentida exclusivamente como Eva ou como Helena, onde o elemento sexual é ainda fortemente acentuado. A banalização do sexo e a interpretação meramente biológico-genital do Eros mostram que o homem não se confronta com o impulso sexual, também como uma força de relação, não exclusivamente genital. Passar para a terceira e a quarta fase da Anima exige verdadeira integração do impulso sexual, sem realçar a sua dimensão biológica e física, mas explorando mais a sua dimensão existencial e espiritual de procura de relacionamento com o feminino tanto no nível arquetípico como pessoal.

A divisão em quatro níveis ou dimensões é procedimento didático, pois o arquétipo da Anima contém potencialmente essas quatro fases. Do mesmo modo, não existe mulher que personifique unicamente uma das dimensões. Cada uma é capacitada potencialmente a personificar Eva, Helena, Maria e Sabedoria. O condicionamento cultural e a falta de mutação no nível arquetípico e pessoal podem fazer com que se permaneça fixo numa das dimensões.

${ }^{44}$ Cf. JUNG, C. G. Praxis der Psychotherapie, GW 16, 1984, §361. Constata-se na Beatriz de Dante, sobretudo na visão teológica de Urs von BALTHASAR, uma confirmação da ideia aqui apresentada. E interessante verificar que VON BALTHASAR dentro de uma perspectiva completamente diferente que a da psicologia analítica, chega à mesma conclusão. Segundo VON BALTHASAR, a figura de Beatriz de Dante é a sabedoria, e é a perfeição da mulher na etapa final. Cf. VON BALTHASAR, H. U. «Eros et agapè, ou: qui est Béatrice?». In: La gloire et la croix. Les aspects estéthiques de la Révelation, pp. 348-366, Paris. Cf. id., pp. 339-360.

${ }^{45}$ Cf. JUNG, C. Praxis der Psychotherapie, GW 16, $\$ 361$. 
Somente na Virgem Maria o feminino alcançou a sua plenitude, pois ela goza de status paradisíaco e vive existência pleromática e divina, ratificada historicamente pela proclamação dogmática da Assunção.

Esse fundo arquetípico, o lado psicológico do "sensus fidelium", nos permite compreender por que C. G. Jung viu tanta importância no dogma da Assunção. Ele diagnosticara, com efeito, no movimento popular exigindo a dogmatização, a existência das próprias leis arquetípicas, procurando a glorificação do feminino, simbolizado na pessoa de Maria, e a necessidade de evolução rumo à Sofia em dimensão pleromática e escatológica. Se Maria já era a realização suprema da Sabedoria no plano histórico, ${ }^{46} \mathrm{com}$ a sua glorificação nos páramos celestes, foi elevada como sabedoria em nível escatológico e eterno, e lhe é atribuída, na nova criação, missão semelhante à da Sabedoria no Antigo Testamento, como auxiliar do Novo Adão, Jesus Cristo. ${ }^{47}$

\section{Maria e o desenvolvimento integral do ser humano na América Latina}

Esse "sensus fidelium" está em vias de assumir nova dimensão na América Latina, ${ }^{48}$ que passou por profundas transformações, tanto no nível eclesial como no social. Pode-se dizer que a Igreja foi fator de transformação da sociedade latino-americana. Nesse movimento de transformação surge também nova mentalidade nas relações humanas. A mulher, que vinha sendo colocada em segundo plano e vivendo em condições de opressão e de humilhação, passa a ser reabilitada aos poucos em sua verdadeira dignidade, como imagem de Deus, tal como é proclamado pelo Documento de Puebla: "A mulher, bem como o homem, é imagem de Deus. 'Deus criou pois o ser humano à sua imagem, criou-os à imagem de Deus, homem e mulher os criou' (Gn 1,27). A tarefa de administrar o mundo, de prosseguir na obra da criação, de serem com Deus co-criadores, cabe pois tanto à mulher como ao homem". ${ }^{49}$

\footnotetext{
${ }^{46}$ Cf. BOUYER, L. Le trône de la sagesse. Essai sur la signification du culte marial. Paris: Cerf, 1957, p. 282.

${ }^{47}$ Cf. EVDOKIMOV, P. La femme et le salut du monde. Paris, 1978, p. 208; JUNG GW, 11, pp. 425-427 (§625); pp. 474-475 (§714); pp. 495-496 (§748).

${ }^{48}$ Cf. CONGREGAÇÃO PARA A DOUTRINA DA FÉ. Instrução sobre a Liberdade Cristã e a Libertação (ILCL). Petrópolis: Vozes, 1986, 97-98.

${ }^{49}$ PUEBLA, 841. Cf. Carta Apostólica Mulieris Dignitatem de João Paulo II, 15/8/1988, (MD) $4,5,10,29$.
} 
A mutação do arquétipo da Anima para a sua mais alta expressão, a Sabedoria ou a Sofia, exige profunda transformação de mentalidade e de atitudes nas relações do homem com a mulher. O documento de Puebla convida contemplá-la com o olhar de Deus, superando a coisificação, a redução a mero objeto sexual, mas percebendo nela a imagem de Deus, o outro que revela Deus, o tu que ajuda o homem a ser eu, pois somente no confronto com a mulher, o totalmente outro, é que o homem se descobre como homem em profundidade. A mulher é companheira, mas também ajuda, auxiliar do homem. "O homem impossibilitado de relação está radicalmente só: o 'direlictus', como diria Heidegger. Talvez seja este justamente o maior pecado de uma sociedade e de uma 'cultura masculina'. A rejeição da mulher se transforma em afirmação de si mesmo, em auto-suficiência. Não se trata aqui de medir certa gravidade social do problema, mas de constatar que a consequência social é o reflexo de um fato muito mais profundo em suas raízes. A presença da mulher aparece no Gênesis (Gn 2,18-25) como a encarnação da proteção, o refúgio contra a indigência e a solidão do homem. A mulher configura uma atividade 'divina'. Ela é o 'ezer', 'kenegdo', isto é, ajuda dele." 50

$\mathrm{Na}$ verdade a promotora dessa transformação histórica é Maria. O documento de Puebla discernira no "sensus fidelium" um novo aspecto do rosto de Maria, pois "nos últimos anos de forma cada vez mais extensa se está articulando outro tipo de piedade, fortemente centrado sobre a imitação de Maria. Nas comunidades de base, nos grupos onde a dimensão política da fé se explicita e se exerce, apreciam-se de modo especial os traços denunciadores, enunciadores, proféticos e libertadores de Maria, presentes em seu hino de louvor, o Magnificat. Este aspecto quase não fora tematizado na tradição mariana e pertence também ao feminino. A imagem que a piedade veiculava e a teologia secundava era a da virgem e mãe meiga, doce, piedosa, humilde, totalmente voltada a Jesus e à sagrada família". ${ }^{51}$

\section{Considerações finais}

Paulo VI, atento também aos sinais dos tempos e ao "sensus fidelium", sublinhara na Marialis cultus a dimensão libertadora de Maria:

${ }^{50}$ SANTISO, M.T.P. A hora de Maria, a hora da mulher. São Paulo: Paulinas, 1982, p. 35. Cf. MD7.

${ }^{51}$ BOFF, L. O rosto materno de Deus: Ensaio interdisciplinar sobre o feminino e suas formas religiosas. Petrópolis: Vozes, 1979, $2^{\circ}$ ed., 196-197. Cf. p. 844. 
a mulher contemporânea... verificará, com grata surpresa, que Maria de Nazaré, apesar de absolutamente abandonada à vontade do Senhor, longe de ser mulher passivamente submissa ou de religiosidade alienante, foi, sim, mulher que não duvidou em afirmar que Deus é vingador dos humildes e dos oprimidos e derruba dos seus tronos os poderosos deste mundo (cf. Lc 1,51-53); e reconhecerá em Maria, que é ‘primeira entre os humildes e os pobres do Senhor' (LG 55), a mulher forte, que conheceu de perto a pobreza e o sofrimento, a fuga e o exílio (cf. Mt 2,13-23) — situações estas que não podem escapar à atenção de quem quiser secundar, com espírito evangélico, as energias libertadoras do homem e da sociedade; e não lhe aparecerá Maria, ainda, como mãe ciosamente voltada só para o próprio Filho divino, mas sim como aquela Mulher que, com a sua ação, favoreceu a fé da comunidade apostólica, em Cristo (cf. Jo 2,1-12), e cuja função materna se dilatou, vindo a assumir no Calvário dimensões universais. ${ }^{52}$

É essa face de Maria que toma forma na América Latina, o que é sinal de esperança não só para este continente, mas também para o conjunto da Igreja. ${ }^{53}$ Puebla: a hora de Maria, a hora da mulher, é o título do livro de Maria Teresa Porcile Santiso, do Uruguai. A América Latina vive o seu "kairòs". "América, esta é a tua hora!", dissera Paulo VI na II Assembleia Episcopal Latino-americana em Medellín. É a "hora da mulher" (Jo 16,20), da mulher Maria, de todas as mulheres. A Maria do Magnificat nos chama à consciência histórica, à participação, à solidariedade. Tudo isto que se torna realidade aos poucos em milhares de comunidades de base, espalhadas por toda a América Latina. ${ }^{54}$

Maria é o oposto da Grande Mãe e da Anima negativa. Somos chamados a nos tornar filhos e filhas adultos na fé, construtores da história. Para Maria, essa construção se dá com o reconhecimento da primazia absoluta de Deus. O Magnificat revela a personificação de Maria como a Sofia, a Anima Sabedoria que nos conduz no mundo do mistério de Deus, e que nos continua

\footnotetext{
${ }^{52} \mathrm{MC} 37$.

${ }^{53}$ Cf. GOLDSTEIN, H. Anwältin der Befreiung. Mariologische Neuansätze in Lateinamerika. Diakonia (nov. 1981) pp. 401-402: "Uma das mais evidentes características do culto mariano na América Latina, é a capacidade de gerar esperança, enquanto entre nós na Europa Central mal alguém ousa falar ainda em futuro e esperança. (...) Somente modelos concretos de fé vivida na esperança... podem ser aqui uma resposta. Futuro somente baseado na mudança e esperança ancorada na convicção de que esta fé convoca para uma transformação libertadora. Maria se apresenta como a Advogada da libertação, como a parceira daqueles que lutam".

${ }^{54}$ Cf. MARINS, J. (et alii), Maria libertadora na caminhada da Igreja. São Paulo, 1986. Cf. tb. Instrução sobre a Liberdade Cristã e a Libertação (ILCL), p. 97.
} 
dizendo como em Caná: "Fazei tudo o que ele vos disser" (Jo 2,5b), e Jesus nos continua dizendo como no Calvário: "Eis a tua mãe" (Jo 19,27). Eis o dogma marial fundamental: ela é Mãe, primeiramente Mãe de Deus e depois Mãe da Igreja, Mãe dos homens, pois ontem como hoje, Jesus se dirige à sua mãe, dizendo: "Mulher, eis o teu filho!" (Jo 19,26b). E como Mãe de Deus e Mãe dos homens, cheia de graça e plena de bondade e de misericórdia, na sua solicitude maternal, como acentua João Paulo II na Redemptoris Mater, que ela continua sua missão de intercessão a favor dos seus filhos e filhas, como Advogada da Redenção. ${ }^{55}$

O Papa Francisco viu a importância da atuação do sensus fidei no processo da nova evangelização, e eis porque a realidade do sensus fidei ou do sensus fidelium não é coisa do passado, mas que aponta para o futuro nos proporcionando fé e esperança. ${ }^{56}$

\section{Referências bibliográficas}

BOFF, L. O rosto materno de Deus: Ensaio interdisciplinar sobre o feminino e suas formas religiosas. Petrópolis: Vozes, 1979.

BOUYER, L. Le trône de la sagesse. Essai sur la signification du culte marial. Paris: Cerf, 1957.

\footnotetext{
${ }^{55}$ Cf. ILCL 97: "Maria é, ao lado do seu Filho, a imagem mais perfeita da liberdade e da libertação da humanidade e do cosmos. E para ela, pois, que a Igreja, da qual ela é Mãe e Modelo, deve olhar para compreender, na sua integralidade, o sentido de sua missão. E notável como o senso da fé dos pobres, ao mesmo tempo que possui uma aguda percepção do mistério da cruz redentora, leva a um amor e uma confiança indefectível para com a Mãe do Filho de Deus, venerada em numerosos santuários". O movimento popular, o "sensus fidei”, sobretudo dos pobres, tem dado sustentação para o dogma marial fundamental, o da maternidade divina de Maria.

${ }^{56}$ Cf. SF 2: “Como resultado, os fiéis têm um instinto' para a verdade do Evangelho, o que lhes permite reconhecer qual é a doutrina e quais as práticas cristãs autênticas e a elas aderir. Esse instinto sobrenatural, que tem uma ligação intrínseca com o dom da fé recebido na comunhão da Igreja, é chamado de sensus fidei, e permite aos cristãos cumprir a sua vocação profética. Em seu primeiro Angelus, o Papa Francisco citou as palavras de uma senhora idosa humilde, que ele havia encontrado certa vez: "Se o Senhor não perdoa tudo, o mundo não existiria"; e o Papa comenta com admiração: "Essa é a sabedoria dada pelo Espírito Santo". ${ }^{2}$ A intuição dessa mulher é uma manifestação marcante do sensus fidei, que, ao mesmo tem-po, lhe permite algum discernimento no que diz respeito às questões de fé, nutre a verdadeira sabedoria e suscita a proclamação da verdade, como neste caso. É, portanto, claro que o sensus fidei representa um recurso vital para a nova evangelização, que é um dos principais compromissos da Igreja de hoje."
} 
COMISSÃO TEOLÓGICA INTERNACIONAL. O Sensus Fidei na vida da Igreja. (SF) (Documentos da Igreja 21) Brasília: Edições CNBB, 2015.

CONGAR, Y. Le peuple fidèle et la fonction prophétique de l'Eglise. Irenikon 24 (1951) pp. 289-312, pp. 440-466.

CONGAR. Y. Jalons pour une théologie du laïcat. (coll. «Unam Sanctam » 23) Paris, 1954, pp. 369-407.

CUCCI, Giovanni, S.J. Il simbolo in Psicanalisi. Il contributo di Jung. Civiltà Cattolica $\mathrm{n}^{\mathrm{0}} 3875$ (2011), pp. 425-530.

DENZINGER, H.; HÜNERMANN, P. Compêndio dos símbolos, definições e declarações de fé e moral (DH). São Paulo: Paulinas/Loyola, 2007.

DILLENSCHNEIDER, C. Le sens de la foi et le progrès dogmatique du mystère marial. Roma, 1954.

EVDOKIMOV, P. La femme et le salut du monde. Paris, 1978.

FISICHELLA, R. Sensus fidei. In: LEXIKON. Dicionário Teológico Enciclopédico. São Paulo: Loyola, 2003, pp. 690-691.

GIUCHEDI, F. Carl Gustav Jung. Aspetti psicologici dell uomo religioso. In: Civiltà Cattolica CXXXII (1981), pp. 250-266.

GOLDSTEIN, H. Anwältin der Befreiung. Mariologische Neuansätze in Lateinamerika. Diakonia (nov. 1981).

CONGREGAÇÃO PARAA DOUTRINA DA FÉ. Instrução sobre a Liberdade Cristã e a Libertação (ILCL). Petrópolis: Vozes, 1986.

HÖFER, J.; RAHNER, K. (org). Lexikon für Theologie und Kirche. Freiburg im Breisgau: Herder, 1955-1967, 1986.

KASSEL, M. Weibliche Aspekte im lukanischen Kindheitsevangelium. Diakonia (Nov. 1984), pp. 391-397.

JOÃO PAULO II. Carta encíclica "Redemptoris Mater" (RM). In: Encíclicas de João Paulo II. São Paulo: Paulus, 1997.

JOÃO PAULO II. Carta Apostólica «Mulieris Dignitatem» (MD), 1984.

JUNG, C. G. Mysterium Coniunctionis. GW 14/1. Olten und Freiburg im Breisgau: Walter Verlag, 1984. 
JUNG, C.G. Zur Psychologie westlicher und östlicher Religion. GW 11. Olten und Freiburg im Breisgau: Walter-Verlag, 1979.

KOSTER, D. Volk Gottes im Wachstum des Glaubens. Heidelberg, 1955.

LUMEN GENTIUM. Constituição Dogmática sobre a Igreja. In: Documentos do Concílio Vaticano II (1962-1965). São Paulo: Paulus, 2001.

MARIN-SOLA, F. L'évolution homogène du dogme catholique. $2^{\mathrm{a}}$ ed. Fribourg, 1924.

MEIRA PENNA, J. O. Em berço esplêndido: Ensaio de Psicologia coletiva brasileira. Rio de Janeiro: José Olimpio, 1974.

NARCISSE, G. Sensus fidei. In: DICIONÁRIO Crítico de Teologia. São Paulo: Paulinas - Loyola, 2004, pp. 1632-1634.

NEUMANN, E. Die Grosse Mutter: Eine Phänomenologie der weiblichen Gestaltungen des Unbewussten. Olten und Freiburg im Breisgau: Walter Verlag, 1981.

PAULO VI. Marialis Cultus (MC). Exortação Apostólica para a reta ordenação e desenvolvimento do culto à Bem-aventurada Virgem Maria, 1974.

PUEBLA - Conclusões da III Conferência Geral do Episcopado LatinoAmericano, 27/1 a 13/2 de 1979.

RADEMACHER, A. Entwicklungsgedanke in Religion und Dogma. Köln, 1924.

SANTISO, M.T.P. A hora de Maria, a hora da mulher. São Paulo: Paulinas, 1982.

SESBOÜÉ, B. O Magistério em questão. Autoridade, verdade e liberdade na Igreja. Petrópolis: Vozes, 2004.

TILLARD, J.-M. R. Le 'sensus fidelium'. Réflexion Théologique». In: Foi populaire et foi savante. Actes du $\mathrm{V}^{\mathrm{e}}$ Colloque du Centre d'études d'histoire des religions populaires tenu au Collège doninicain de théologie (Ottawa). (Cogitatio Fidei 87) Paris: Cerf, 1976.

TILLARD, J.-M.R. «Théologie et vie ecclésiale». In: Initiation à la pratique de la théologie, $t$. I, Paris, 1982, pp. 161-182.

TILLARD, J.-M. «Teologia e Vida Eclesial». In: LAURET, B.; REFOULÉ, F. (Org.). Iniciação à prática da teologia. Tomo I: Introdução. São Paulo: Loyola, 1992. 
UNTERSTE, H. Theologische Aspekte der Tiefenpsychologie von C.G.Jung. Düsseldorf, 1977.

VON BALTHASAR, H. U. «Eros et agapè, ou: qui est Béatrice?». In: La gloire et la croix: Les aspects estéthiques de la Révelation. Paris, 1968.

Pedro K. Iwashita

Doutor em Teologia pela Universidade de Fribourg (Suiça)

Professor da Faculdade de Teologia na PUC/SP

São Paulo / SP - Brasil

e-mail: iwashita@uninet.com.br

Recebido em: 05/03/15

Aprovado em: 06/09/15 